\title{
Where Have All the Behaviorists Gone?
}

\author{
Marc N. Branch and E. F. Malagodi \\ University of Florida
}

\begin{abstract}
Many of the world's current problems are the result of behavior, and traditional appeals to mental determinants are again proving inadequate. The time for a behavioristic alternative appears ripe, yet many behaviorists seem to be becoming less behavioristic and more mentalistic. When confronted with the complexity of human behavior many are resorting to the intellectual comfort and safety of mentalism. A recent example of this tendency (Schwartz et al, 1978) is presented and discussed. Additionally, speculations regarding the origins of the resurgence of mentalism are presented, and it is proposed that arranging histories which provide for more rigorous and lasting control of verbal behavior about behavior may serve to improve the situation.
\end{abstract}

The writing of this paper originated during a recent academic term when each of the authors was teaching a course in the philosophy and application of behaviorism. Over the course of the term we and our students became increasingly convinced that many of today's world problems to a considerable extent are due to the western world's preoccupation with mentalistic "explanations" of both troublesome and potential problemsolving behaviors. Our general opinions, of course, are hardly new. Skinner (1953, $1969,1971,1974)$ has argued forcefully that a behavioristic approach to environmental-behavioral problems is one that leads directly to prescriptions for action. Nevertheless, public officials continue to attribute our problems to such entities as a "crisis of confidence" and tell us that to overcome our problems we must "increase our confidence." Thus our problems, supposedly caused by our

Preparation of this paper was aided by USPHS Grant No. DA-01417 from NIDA. A version of the paper was presented at the annual meeting of the Association for Behavior Analysis, Dearborn, MI, June, 1979. The authors thank Alice Nippes for secretarial assistance. Reprints may be obtained from either author, Psychology Dept., University of Florida, Gainesville, FL 32611. lack of confidence, can be ameliorated simply by a change in some mental state. Overlooked in such accounts are the influences that lead people to say that they are confident, and those influences lie in the contingencies arranged by our environment. The things that we can do something about do not reside in the minds of men, but rather exist in the directly manipulable aspects of our world.

We are overpopulating the planet, exhausting our resources with geometric acceleration, engaging in excessive agressive behavior, and spending as yet unacquired money at a frightening pace. All of these problems, of course, are behavioral and appeals to the good will of men as well as attempts to change their minds are working no better now than they have for the past 2500 years. As Skinner (e.g. 1971) has so often argued, a profitable venture might be to explore behavioristic alternatives. That is, by divesting ourselves of mentalistic interpretations we may draw attention to manipulable aspects of the environment that will possibly allow us to deal more effectively with the serious problems we face.

The existence of a behavioristic alternative depends to a large extent on the ex- 
istence of a group committed to its tenets, and the development and survival of such a group requires that new, behavioristic terms come to be used consistently in the description of behavior. Being products of a western verbal community we all have been taught to speak and presumably to think in mentalistic terms, but in the late 1950's and on through the 1960's a special verbal community developed whose members practiced the experimental analysis of behavior (EAB). This community was characterized by a commitment to functional analyses and an explicit avoidance of mentalistic accounts of behavior. What better approach to problems than a pragmatic, functional one? More recently, however, verbal behavior in the EAB verbal community seems to be changing.

What's so important about verbal behavior of psychologists? Is it not the nonverbal behavior of such persons that is of importance? That is, is it not all right to "talk funny" if you do the "right" things? The answers to these questions lie, we believe, in some of the basic tenets of radical behaviorism. Consequently, we feel obligated to discuss briefly those aspects we think are important to our argument. This obviously will be a review for many and for that we apologize, and we shall try to be brief so that we may return to the issue of control of verbal behavior.

Radical behaviorism can be distinguished not only from traditionally mentalistic schools of psychology, but also from both methodological and "cognitive" behaviorism on the basis of the position taken with respect to private events. There are two main classes of private events and two main issues concerning them. The two classes are 1) felt states of the body (mediated by proprioceptive and interoceptive nervous systems) and 2) private behaviors such as thinking, seeing, etc. The two main issues with respect to these private events are 1) their scientific or pragmatic status, i.e., the "measurement" problem and 2) their causal status. Private events are a problem for science because they are private. Only the individual observes his private behavior and stimuli. Other members of the community "know about" them largely on the basis of the individual's verbal report. His verbal report of his private events is a product of a verbal community that has access only to associated public conditions. Thus, only to the extent the public conditions that are used by the verbal community are perfectly correlated with private events can we expect accurate descriptions. The issue is further confounded by other determinants of verbal behavior which may lead someone to "lie." Thus our knowledge of the private events of others as well as our ability to describe our own are not as scientifically secure as is our knowledge of the external world, and depend critically on a functional analysis of verbal behavior, especially of its acquisition (Day, Note 1). "Cognitive" behaviorists are currently trying to deal with private events in the absence of this analysis, whereas methodological behaviorists simply ignore private events. A radical behaviorist, by contrast, recognizes the observability of these private events, but notes that their systematic use in an effective technology will be provided only following a thorough and definitive analysis of the verbal contingencies giving rise to reports of private events.

The second, and more fundamental issue with respect to private events has to do with the role of private events in the explanation of behavior. Radical behaviorism eschews bestowal of causal status to private events. Why? One reason has to do with the measurement issues just described. More important is the interpretive view of private events. For the radical behaviorist private events are best considered usually as results, not causes. Private stimuli can be thought of as coincidental, collateral products of events that result in overt behavior, and private 
behavior must be accounted for in the same way that public behavior is.

Speaking logically, of course, private events that occur reliably before public ones (and that satisfy in some sense the criteria of necessity and sufficiency) could be considered as "causes." To stress the importance of private events in determining behavior, however, leads one almost necessarily to place emphasis on events that are poorly defined and inaccessible. The real problem, then, is one of accessibility. Private events are not accessible and therefore not directly manipulable. They provide prescriptions for action based on indirect manipulations of things unseen.

Another crucial facet of the radical behavioristic position qhe distinction between rule-governed and contingencyshaped behavior. Rule-governed behavior comprises a large portion of human activity, and is vitally important. No one can be exposed to all of the contingencies of the world in a single lifetime, so rules are very efficient. Rules and rulegoverned behavior are especially important aspects of the scientific enterprise. The business of science is to analyze environmental contingencies and then to formulate rules on the basis of those analyses. Being exposed to rules of course is not the same as being exposed to the contingencies, and rule-governed behavior may be less resistant to change than is behavior that is contingency shaped. Analyses of differences between rule-governed and contingency-shaped behavior would shed light on this supposition.

Since so much of science is rulegoverned behavior we find the verbal behavior of scientists exceptionally important, and we are concerned that the rules outlined above about private events seem to be exerting less and less control over the verbal behavior of many behavior analysts. Take, for example, the following quotes:

\footnotetext{
"It may be more accurate to say that some inter-
} nal trace or representation may serve as a cue."
"Perhaps the US-US interval engendered some sort of Gestalt perceptual organization."

"Duration of the sample stimulus may be encoded as an additional stimulus attribute."

“... (S)ubjects learned a representation of the sentence..."

These quotes are not from the Journal of Verbal Learning and Verbal Behavior but rather are from a recent issue of the Journal of Experimental Analysis of Behavior (JEAB). JEAB is one of the main communicative vehicles for the $\mathrm{EAB}$ community and was founded initially on a radical behavioristic base. The appearance in this journal of blatantly mentalistic statements such as those given above indicates a change in the control of verbal behavior. Some argue that authors should be free to speak as they wish as long as they present objective data before they do so. We could not disagree more. We find the verbal behavior of scientists exceptionally important because the precision of specification of rules generated from a science determines both the success and utility of that science. Thus, it should be clear that we do not believe that it is "all right to talk funny if you do the right things."

What we should like to do now is present a somewhat extended example of change in verbal control and try to refute its claims. Then we shall speculate on the origins of such changes and offer some modest prescriptions (that is, rules) for rectification. Specifically we would like to deal at some length with a paper by Schwarz, Schuldenfrei and Lacey that appeared recently in Behaviorism (Schwartz et al., 1978). The paper is entitled "Operant Psychology as Factory Psychology."

The paper makes many points but we shall deal with the two we find most significant (1) the "naturalness" of operant conditioning and (2) the role of mental events in human behavior. The authors begin by charging that operant conditioning is not natural, i.e., that it does not occur (or at least that it accounts for very little) in the "natural" environment. The authors assert that field ap- 
plications of operant principles are also unnatural when they say

"Applications of operant principles to social institutions may tranform those institutions so that they conform to operant principles."' (p. 229)

And to show that their criticism is not confined solely to applied behavior analysis they also state that

". . . methods of behavior analysis . .. in the animal laboratory ... (1) virtually guarantee the confirmation of principles of behavior analysis . . . (2) may be atypical of the normal settings in which the organism behaves . . . (3) do not normally manifest certain processes operative in the natural environment . . . (4) produce behaviors with characteristics significantly different from much in the natural environment." (p. 231)

They argue then that application of contingencies make the contingencies effective and, to paraphrase, say that research in EAB tells us what can be but not what is. Consequently, such research leads us to give up any aspiration about discovering fundamental truths about human nature. It is fortunate that these authors can identify fundamental as opposed to derived truths, and it is also interesting that the fact of operant conditioning apparently is not fundamental.

Interestingly, Schwartz et al. distinguish operant from biological determinants of behavior. Apparently, the process of operant conditioning is not biological. As we understand it, the term "operant" is no less biological than the term "species." There seems to be a recent tendency to describe conditioning processes as something other than biological in spite of the fact that living tissue is generally required for the demonstration of such conditioning. The facts of operant conditioning depend no less on genetic factors than do the facts of metabolism. Both are presumably the result of natural selection, so to separate them or any other processes observed in living organisms into biological and nonbiological categories is not warranted. Operants are no less biological than any other term referring to properties of living things.

Schwartz et al. also try to make use of the anecdotal data of the Breland's
(Breland and Breland, 1961) on phylogenically controlled behavior to argue that the facts of operant conditioning

“. . . may be oed under a limited set of conditions which systematically prevent the occurrence of other kinds of influences." (p. 236)

Such a statement, it seems to us denies the existence of the applied behavior analysis movement which has shown ad infinitem that the facts of operant conditioning can be observed in a myriad of loosely constrained settings (see, for example, Journal of Applied Behavior Analysis, 1968-1979).

Next Schwartz et al. take on a favorite "real world" case in which operant principles seem clearly to be in operation-the case of the factory worker. It is here that we believe the authors make a serious formalistic error. They note the repetitive nature of the work and draw the analogy to the laboratory free-operant. They conclude erroneously, however, that because of the formal similarities of the two situations that the laboratory analysis has functional relevance only to the formally analogous factory work situation. Thus, they grant that operant principles seem to apply to factory workers. What they argue next, however, is that a factory worker's behavior conforms to operant principles only because it was made to as a result of the scientific management movement of the late 19th and early 20th centuries (see Taylor, 1967). This movement dictated the division of labor and wages for work done. They contrast a factory worker's behavior with that of a feudal serf, and they find few similarities. A serf's work was diversified and varied, and seemed not nearly as repetitive as a modern factory worker's. Another distinction that they draw is between reasons for working. The factory worker works for wages. The serf, by contrast, worked "within a framework of legal and social obligations ..." (p. 240). The implication is that somehow such a framework is devoid of contingencies. For example, they say that there is 
"No explicit evidence from the nature of their social obligation that the serfs' work was 'reinforced' on 'schedule'."

To us this implies that their work was without consequences which did not occur according to any schedule, two clear impossibilities by definition. Schedules simply describe relations among behavior and stimuli, so all events occur according to some schedule. Just because the arrangement may not be one of the classic "big four" (variable interval, variable ratio, fixed interval, fixed ratio) does not mean schedules do not exist and operate.

They argue that the laboratory analysis of behavior is not relevant to serf work because such work did not involve simple, repetitive tasks. This argument, we believe, is a result of a misunderstanding of the analytic nature of the free-operant paradigm. Use of the free-operant is an analytic tool and was never meant to be directly analogous to "real life." Laboratory experiments are rarely successful when "real life" is simulated. They tend to be more successful when issues of measurement, convenience, control and the like are attended to.

The main point that Schwartz et al. argue is important for Skinnerian radical behaviorists. Their suggestion that operant behavior is "unnatural" challenges the Skinnerian suggestion that behavior already is controlled to some extent by contingencies of reinforcement, but haphazardly (and also often aversively) (Skinner, 1971). From the Skinnerian point of view, then, application of formalized contingencies does no "fundamental" damage. From the point of view of Schwartz et al., application of such contingencies results in the modification of the "natural order" of things.

It should be obvious that we think the arguments of Schwartz et al. are weak. They rest not only on formalistic extrapolation, but also on what we consider to be a misunderstanding of the concept of the operant. They assume that because serf work was not extremely repetitive and not made up of small, discrete units that it was not operant in nature. The concept of the operant is certainly not so restricted as to apply only to easily repeatable, laboratory free operants. Even in the research literature, operants have extended from twitches of individual muscle fibers (Hefferline et al., 1959) to generalized, abstract classes such as imitation (Baer et al,, 1967). Operants are as operants do; that is, they are functionally defined units of analysis.

Suppose that we accept the assertion of Schwartz et al. that operant behavior is not natural and that it does not provide a realistic account of behavior. What do they offer as an alternative approach? They offer us mentalism. They say

\footnotetext{
"Human behavior is differentiated from animal behavior most importantly by the fact that the former, but not the later, can involve intelligent choice of both ends and means, and such choices are in no way determined by anything remotely resembling a past history of reinforcement of such behavior. Intelligent choice is largely determined by anticipated consequences."' (p. 249)
}

Not only do we find a mentalistic account (intelligent choice), we also encounter the blatant disclaim that this activity may be related to past histories of reinforcement for choosing (in no way relates to ....). Finally, we find that this mentalistic action is determined by yet another mental activity (anticipation) which, presumably, is also not related to past environmental consequences. Nothing could better exemplify the kinds of difficulties involved in regressive retreats to mentalism as "solutions" for dealing with the complexity of human behavior. It is not clear what prescriptions for action are dictated by such an account. Are we to attempt to modify "intelligence," "choice," or "anticipation'? To attempt to address any of these "targets" without changing histories of reinforcement, one must admit, is indeed a challenging assignment.

Mentalism is remarkably seductive. Private behaviors and stimuli often occur immediately before observable behavior and thus easily come to be considered as 
unitary causes. Recall, however, that private behaviors and stimuli suffer the fundamental weakness of inaccessibility. We must, if we are to achieve a functional (rather than armchair) analysis of behavior, determine the variables of which both observable and presumably private behaviors are a function. To do this we must accept the notion of action at a temporal distance. There is nothing inherent in the notion of causality that dictates that causes must occur immediately before effects. The accessible causes of behavior are historical. Why is it that few have problems with the assertion that today's performance by an animal in the laboratory is a function of yesterday's fixed-ratio (FR) schedule, while at the same time being unable to accept that today's human behavior is a function of something that happened a longer time ago? Where is the difference? Even the animal under the FR contingency has a temporally remote shaping history that is a crucial determinant of current behavior. We gain nothing in terms of prediction and control by postulating some cognitive representation of lever pressing in our animal subject. Instead we obscure the controlling variables by appealing to such hypothetical entities.

For those who may be unaware, Dr. Schwartz is currently a member of the editorial board of JEAB, so his attack is not coming from outside, but rather from within the EAB establishment. This paper, of course, is but one example of the recent retreat to mentalism. The growing emphasis on "Cognitive behavior modification" also signals the trend. Notably, a reviewer of the most recent authoritative handbook on the laboratory analysis of behavior (i.e., Honig and Staddon, 1977) remarked that laboratoryoriented behavior analysts also seem to be deviating from attempts to determine objective functional relationships. He surmised that

\footnotetext{
"If one cannol play with the direct aspects of behavioral control, then perhaps the only alternative is to play with the words." (Ferster, 1978, p. 349)
}

What has happened to produce this state of affairs? Surely it cannot be that behaviorists recently and suddenly discovered their own private behaviors. We submit that a vast majority of the shift is a reflection of changes in rulegoverned behavior.

It wasn't so long ago that the spark of commitment to behaviorism glowed brightly. That spark is barely visible these days as repeated Mentalistic micturitions have dampened it. Mentalistic psychologists, against whom we were once so squarely pitted, have outwitted us. Behaviorists have largely failed to develop cohesive training programs within major Ph.D. granting institutions. With few exceptions (e.g., University of Florida, Western Michigan University, University of West Virginia), a single "token Behaviorist" usually finds him or her self isolated in a department composed of mentalistic psychologists and residing in diverse "areas" such as "social psychology," "developmental psychology," "learning," etc. In these environments, the fledgling behaviorist eventually succumbs to the reinforcement and punishment practices of the immediate verbal community. Individual fledgling behaviorists have usually found themselves surrounded by mentalists who eventually come to control the behavior of the poor former behaviorist. These mentalists pay lip service to some of our more powerful methods to demonstrate to us their open-mindedness, and then reinforce our open-mindedness in accepting mentalistic concepts. They take advantage of our pre-graduate school, excessively mentalistic history, and soon (often before the tenure deadline) the former behaviorist is acknowledging the central role of cognitions (i.e., mental events) in the determination of behavior. Their task has been made easier by the view that behavioristic procedues are best used as band-aids to fix bad behavior.

How have we let this happen? Are we doomed to pursue the mentalistic path for 
the 297th time in history? This may be our last opportunity to address the issue if the world continues on its present course.

The problem has several correctable origins. First, mentalists control most of the important scientific and technological resources. For example, across all the advisory committees at the Alcohol, Drug Abuse and Mental Health Administration there are currently very few persons who would probably call themselves radical behaviorists (DHEW, 1979). These committees control most of the Federal funds that go toward behavioral research. Control of such committees by mentalists is insidious because not only are current researchers not supported, but such committees also can have considerable impact on training. So far as we know there is not one federally funded graduate training program in behavior analysis in this country. If behaviorists are to improve the situation then they must engage in the behaviors, political though they may be, to get some control over these resources.

Another area where we must improve if we are to prevent radical behaviorism from being swept under the rug is to improve our training of behaviorists, especially of our applied behavior analysts. How should we do this? Perhaps we can take a lesson from a period when behaviorism really flourished, the 1960's. Successful and dramatic applications of behavioral principles abounded in the 1960 's, and the reports of them were unfettered by gratuitious references to mental events. Why was this the case, and why is it not the case now? Of course no one knows, but there is at least one correlate we find interesting. The breakthroughs in applied behavior analysis were performed by persons, e.g. Wolf, Baer, Michael, Azrin, et al, who had begun their training as laboratory scientists. Today's "applied behavior analysts," at least a majority, have never been in a laboratory let alone performed experiments there. Our suggestion is that effective behavioral skills, as well as a basic appreciation for the power of a behavioral analysis, are born in the contingencies in the lab. That is, to be a good behaviorist requires that behavior with respect to behaviorism be contingencyshaped as well as rule-governed. We fear that by and large, the training of behaviorists has come to emphasize rules and rule-governed behavior to too great an extent, rendering such behavior easily changeable.

Whatever we do, if we expect radical behaviorism to survive, (and as Skinner has argued, survival is the true test), we must do a better job of training our students. We must provide them with a history that will render them immune to the seductive security of mentalism so that when exposed to their mentalistic colleagues, they can persevere in their attempts to isolate and control the manipulable variables of which behavior is a function.

\section{REFERENCE NOTE}

1. Day, W. On the difference between radical and methodological behaviorism. Presented at meeting of Midwestern Association for Behavior Analysis, Chicago, May, 1977.

\section{REFERENCES}

Baer, D. M., R. F. Peterson and J. A. Sherman. The development of imitation by reinforcing behavior similarity to a model. Journal of the Experimental Analvsis of Behavior, 1967, 10, 405-416.

Breland, K. and Breland, M. The misbehavior of organisms. American Psvchologist, 1961, 16, 681-684

DHEW. HRA, HSA, CDC, OASH, \& ADAMHA Public Advisory Committees, Authority, Structure, Functions, Members, Nov. 1, 1978. DHEW Publication No. HRA 79-601, 1978.

Ferster, C. B. Is operant conditioning getting bored with behavior? Journal of the Experimental Analysis of Behavior, 1978, 29, 347-349.

Hefferline, R. F., B. Keenan, and R. A. Harford. Escape and avoidance conditioning in human subjects without their observation of the response. Science, 1959, 130, 1338-1339.

Honig, W. K. and Staddon, J. E. R. (Eds). Handbook of operant behavior. Englewood Cliffs, New Jersey: Prentice-Hall, 1977.

Schwartz, B. Schuldenfrei, R. and Lacey, H. Operant psychology as factory psychology. Behaviorism, 1978, 6, 229-254. 
Skinner, B. F. Science and human behavior. New York: Free Press, 1953.

Skinner, B. F. Contingencies of reinforcement: $a$ theoretical analysis. New York: AppletonCentury-Crofts, 1969.
Skinner, B. F. Beyond freedom and dignity. New York: Alfred A. Knopf, 1971.

Skinner, B. F. About behaviorism. New York: Alfred A. Knopf, 1974.

Taylor, F. W. Principles of scientific management. New York: W. W. Norton, 1967. 